\title{
Coulisses
}

Revue de théâtre

15 | Hiver 1997

Varia

\section{Machine à café}

Jean-Marc Cuccuru

\section{(2) OpenEdition}

Journals

Édition électronique

URL : http://journals.openedition.org/coulisses/5188

DOI : $10.4000 /$ coulisses. 5188

ISSN : 2546-9460

\section{Éditeur}

Presses universitaires de Franche-Comté

\section{Édition imprimée}

Date de publication : 1 janvier 1997

Pagination : 69-70

ISSN : 1150-594X

\section{Référence électronique}

Jean-Marc Cuccuru, « Machine à café », Coulisses [En ligne], 15 | Hiver 1997, mis en ligne le 26 avril

2019, consulté le 29 octobre 2019. URL : http://journals.openedition.org/coulisses/5188 ; DOI :

10.4000/coulisses.5188

Ce document a été généré automatiquement le 29 octobre 2019

Coulisses 


\section{Machine à café}

\section{Jean-Marc Cuccuru}

« Duel : ... conflit, antagonisme, lutte entre deux personnes ... ou entre des sentiments, des tendances opposées. "

(Grand dictionnaire encyclopédique Larousse) «Il ne lui viendrait jamais à l'esprit que puisse s'établir entre lui-même et un objet une quelconque relation. » 
1 Monsieur Jeandrot exerce une légère pression sur le fil en partie dénudé de la machine à café. Le voyant lumineux s'allume. Les doigts relâchent leur pression. Le voyant lumineux s'éteint. M. Jeandrot saisit à nouveau le fil, le déplace de quelques centimètres, puis exerce derechef une légère pression à l'endroit où le chatterton se décolle. Le voyant lumineux s'allume. Quelques minutes plus tard, il est 7h32, le café coule dans le bol en grès qui remplace le pot en verre, cassé depuis longtemps. Le café est à peine tiède. M. Jeandrot constate que l'eau qui s'écoule du réservoir de la machine à café n'a presque pas chauffé. Il éteint la cafetière. Quelques minutes plus tard, après avoir ingurgité la potion tiède dont l'amertume est adoucie à renfort de sucre, il quitte son appartement, un petit trois pièces dont il est le propriétaire, dans le centre ville, et se rend à son travail.

2 M. Jeandrot a hérité de ce logement de sa tante, non qu'il eût entretenu avec d'excellents rapports expliquant qu'elle se fut souvenue de lui au moment de rédiger son testament; simplement, il se trouvait être son unique descendant encore en vie. Cet héritage opportun lui octroya une certaine liberté dans la mesure où il put alors se permettre un peu de laisser-aller dans la gestion de ses dépenses ; c'est à dire qu'il ne devint pas moins économe : il cessa progressivement de tenir à jour ses comptes.

3 «- Être propriétaire de son logement, Jeandrot, c'est sacrement de soucis en moins ", lui répétait souvent son collègue Bernard, qui ajoutait invariablement que « ce n'est pas avec le salaire qu'ils avaient, lui ou Jeandrot, qu'ils pourraient s'acheter le paradis. »

4 M. Jeandrot acquiesçait, puis reprenait le tri des mandats. M. Jeandrot travaille à la Poste Centrale, il officie au guichet "Courrier et Mandats Internationaux.» Depuis plusieurs mois il a tendance à arriver à son travail légèrement en retard. Un léger retard sans conséquences dans la mesure où il pourra le rattraper en fin de journée ; mais aux yeux de certains de ses collègues il est clair que $M$. Jeandrot cherche à se « distinguer ». Il faut convenir que M. Jeandrot ne fait rien pour obtenir un peu de compréhension de la part de ses collègues. Que peut-il dire? Qu'il est légèrement en retard parce que sa machine à café est âgée, fonctionne mal, que chaque matin il perd de précieuses minutes pour tenter, parfois sans succès, de la faire fonctionner ? Bien sûr ses collègues lui diraient de s'en acheter une neuve, après tout, avec ce qu'il économise du fait qu'il est propriétaire, il peut bien se permettre de s'acheter ce que bon lui semble. Il existe d'excellentes "promos » tout au long de l'année. Il suffit de regarder les prospectus dans la boîte aux lettres. Cependant M. Jeandrot ne regarde pas les prospectus. Il ouvre de moins en moins souvent son courrier, rare de toute façon, se bornant généralement à expédier les factures. Il ne fréquente plus les centres commerciaux. Il fait ses courses au «Shopi » du coin. C'est là qu'il achète son café, du «Carte Noire Pur Arabica »; celui-ci ou un autre ; quoi qu'il en soit sa machine à café, ainsi qu'il la nomme, donne des signes évidents d'usure. Le cordon électrique est couvert de différentes couches de chatterton tout racorni ; les fils sont en grande partie dénudés au niveau de la prise que $M$. Jeandrot doit systématiquement saisir de manière délicate entre le pouce et l'index afin d'éviter tout « coup de jus ». Malgré d'incessants détartrages la machine semble constamment entartrée; l'eau ne s'écoule qu'avec parcimonie pendant un temps qui paraît démesurément long. Parfois la machine s'emballe et l'eau surgit, pour une fois bouillante, telle un geyser, éclaboussant tout alentour, sans pour autant se déverser sur le café qui reste sec dans le filtre. $\mathrm{M}$. Jeandrot ne conserve pas sa vieille machine à café pour des motifs sentimentaux. Il ne refuserait pas d'en changer si quelqu'un (mais qui ?) lui en offrait une neuve. Il 
n'aime ni ne hait sa machine à café; il ne lui viendrait jamais à l'esprit que puisse s'établir entre lui-même et un objet une quelconque relation. Malheureusement M. Jeandrot apprécie le café, il aime sa chaleur, l'amertume qu'il laisse dans la bouche, la vapeur qui embue ses lunettes lorsqu'il porte le bol en grès à ses lèvres. Se rendre à son travail sans avoir bu son café lui est aussi inconcevable que de sortir dans la rue pieds nus dans ses chaussures. Depuis que sa machine à café donne des signes évidents d'épuisement, l'humeur de M. Jeandrot s'est altérée. Il n'a certes jamais été un bouteen-train mais depuis plusieurs mois son comportement inquiète son chef de service.

Le matin du drame, M. Jeandrot a cassé son bol en grès. Habitué à la fadeur tiédasse de son café il avait, dès que celui-ci était "passé ", jeté deux morceaux de sucre catégorie 4, agité nerveusement la cuiller dans le bol avant de le porter à ses lèvres. Cependant, cette fois-ci, le café était bouillant - habituellement, quand la machine déversait de l'eau bouillante, elle surgissait pour se déverser partout excepté dans le bol en grès. Cette fois l'eau s'était écoulée normalement. Les lèvres et la langue en feu, M. Jeandrot avait étouffé un cri, par réflexe sa main avait lâché le bol dont le contenu avait copieusement arrosé ses chaussures, ses chaussettes, le bas de son pantalon. Il était inconcevable qu'il se rende à son travail dans cet état. Il avait changé de tenue, s'énervant après les lacets de ses chaussures, et était parvenu très en retard à la Poste Centrale. Un esclandre avait eu lieu. Son collègue Bernard lui avait proposé, en guise de boutade, de lui offrir une horloge. M. Jeandrot, si calme d'habitude, l'avait saisi par le col. Des échanges verbaux avaient été proférés. N'eût été l'intervention du chef de service la situation eût pu empirer. M. Jeandrot s'était rendu aux toilettes, pour se remettre. Il s'était aspergé le visage à l'eau froide, s'était observé longuement dans la glace au-dessus du lavabo. S'était redressé. Voilà. Il appuie ses mains sur le bord du lavabo. Il redresse la tête. Inspire fortement l'air dans ses poumons. Baisse les paupières. Expire. Relève les paupières. S'essuie les mains. Renoue le nœud de sa cravate. Puis sort des toilettes et se rend à son guichet.

6 En fin de matinée, peu avant midi, un client dépose devant lui un colis. M. Jeandrot dit, "pour les colis c'est le guichet cinq". Le client répond ça fait vingt minutes qu'il attend, il va pas faire la queue une seconde fois, et comme il est bientôt midi la poste va fermer et il n'a pas l'intention de revenir à deux heures. M. Jeandrot avait relevé la tête, avait haussé légèrement la voix. « Pour les colis c'est le guichet cinq, ici vous êtes aux Courriers et Mandats Internationaux ». Le client avait lui aussi haussé le ton. M. Jeandrot s'était levé, était passé derrière le guichet puis avait saisi le client à la gorge. «Comme s'il voulait l'étrangler, Monsieur le Directeur ». Des personnes s'étaient interposées. M. Jeandrot maîtrisé par des clients et le personnel de la poste. M. Jeandrot muet, les yeux brillants de rage. Le client soutenu par quelques personnes, le visage congestionné. Des cris. De l'agitation. Des allées et venues. «Des excuses, Monsieur le Directeur », « M. Jeandrot suivez-moi ». Mise à pied. Blâme. " Mais au regard des états de service... Quelques jours de repos... M. Jeandrot depuis quand n'avez-vous pas pris de congés? ».

7 Et là, stupéfaction. La fiche de congés est vierge. Celle de l'année précédente également. Exclamations. Le Chef de Service s'expliquant. Congés gérés par ordinateur. Impossible de vérifier. Tout le monde pensait que. Impensable. M. Jeandrot en congé d'office pour trois semaines. Convocation Médecine du Travail dès retour. «La mer ou la montagne Jeandrot reposez-vous prenez l'air ». On avait parlé de moments difficiles. On connaît tous ça. Se serrer les coudes. 
M. Jeandrot est installé dans la cuisine. Assis sur une chaise, il fait face à la machine à café. Son repas est fini. Saucisse à la poêle, petits pois, fromage. M. Jeandrot verse le fond de la bouteille de vin dans son verre. Il se lève, verre en main, s'adosse au radiateur. Il est légèrement ivre. Il boirait volontiers un café. Il sort un bol en grès d'un placard, l'emplit d'eau chaude qu'il verse dans le résevoir de la cafetière. Place un filtre neuf. Verse le café. Branche la machine et exerce une presion sur le fil dénudé. Le voyant lumineux s'allume puis s'éteint dès que les doigts relâchent leur pression. M. Jeandrot saisit à nouveau le fil, le déplace puis exerce une pression à l'endroit où le chatterton part en lambeaux. Le voyant lumineux s'allume. Pendant que le café coule M. Jeandrot dessert la table de la cuisine et fait la vaisselle. Il vient de finir de gratter la poêle à frire. Il la rince puis la pose sur l'égouttoir. Il replonge les mains dans le liquide. Il perçoit un bruit. Une sorte de grésillement. Il tourne la tête. Une étincelle jaillit du cordon dénudé de la machine à café. $M$. Jeandrot, les doigts pleins de mousse, saisit la machine à café. Le bol en grès tombe et se brise. Le café éclabousse ses chaussons. Quand M. Jeandrot plonge la machine, toujours branchée, dans l'évier, une petite flamme court le long du cordon.

\section{AUTEUR}

JEAN-MARC CUCCURU

$2^{\mathrm{e}}$ prix ; prix du CRL 